\title{
Monolingual Dictionary Use in an EFL Context
}

\author{
Holi Ibrahim Holi Ali ${ }^{1}$ \\ ${ }^{1}$ School of Education \& Professional Development, University of Huddersfield, UK \\ Correspondence: Holi Ibrahim Holi Ali, PhD Student of Applied Linguistics \& TESOL, School of Education \& \\ Professional Development, University of Huddersfield, UK. Tel: 96-892-295-223. E-mail: howlli2@yahoo.com
}

Received: April 9, 2012 Accepted: May 2, 2012 Online Published: July 1, 2012

doi:10.5539/elt.v5n7p2 URL: http://dx.doi.org/10.5539/elt.v5n7p2

\begin{abstract}
Caledonian College of Engineering, Oman, has been encouraging its students to use monolingual dictionaries rather than bilingual or bilingualized ones in classroom and during the exams. This policy with has been received with mixed feelings and attitudes. Therefore, this study strives to explore teachers' and students' attitudes about the use of the dictionary and its training. Questionnaires were administered to 20 teachers and 100 students to collect their perceptions about the use of monolingual dictionaries at the expense of bilingual dictionaries. The results revealed that the vast majority of the teachers prefer their students to use monolingual dictionaries because they will help them acquire foreign language more effectively and that the bilingual dictionaries are likely to encourage translation, whereas most of the students would prefer to use bilingual and bilingualized dictionaries because they feel they are practical and easy to use. The study puts forward some recommendations and strategies for the effective use of the dictionary, the basis of a good learner dictionary, challenges of using monolingual dictionaries and possible training strategies for dictionary use.
\end{abstract}

Keywords: monolingual dictionary, EFL context, bilingualized dictionary, bilingual, dictionary use training, vocabulary acquisition

\section{Introduction}

Dictionaries are an indispensible tool for mastering vocabulary and learning a foreign language in general. It provides learners with access to a vast amount of information about words and their usage. Using dictionaries can be seen as an explicit strategy for learning a foreign language vocabulary or as communication strategy. According to Pousi (2010) "vocabulary acquisition is considered by many to be the single most important aspect of foreign language learning" (p. 21). Furthermore, Knight (1994) says "not only the majority of students studying foreign language cite vocabulary as their number one priority, but it is often considered a priority by teachers as well" (p. 1). Therefore, he considers the study of vocabulary to be the heart of language teaching in terms of organization of syllabuses in addition to the evaluation of learner performance, and the provision of learning resources (1994, p. 2).

For many years, School of Foundation Studies, Caledonian College of Engineering, Oman has been encouraging its students to use monolingual dictionaries in the classroom and during the exams because they believe that monolingual dictionaries are useful for the students and they can help them to learnbetter. This policy has been received with mixed feelings and attitudes and resentment from students and some teachers felt that using dictionaries during lessons would waste their time and slow doing teaching. This study is carried out based on several observations in the classroom which revealed that most of the students (if not all) prefer to use bilingual dictionaries and electronic dictionaries rather than the monolingual ones. This observation is corroborated by studies carried out by (Atkins \& Knowles, 1990; Bejoint \& Moulin, 1987; Laufer \& Hadar, 1997; as cited in Loucky; 2003) which revealed that bilingual /bilingualized dictionaries in general and electronic dictionaries in particular, appear to be much more effective than monolingual book dictionaries for the acquisition of L2. Therefore, the main aim of conducing this study to investigate students' and teachers' opinions about the currently used dictionaries, find out better ways for using them and the kind of dictionary students and teachers prefer to use.

\section{Literature Review}

\subsection{Does It Matter What Sort of Dictionaries EFL Learners Use?}

Dictionary is considered to be an effective tool for helping learn vocabulary in a second or a foreign language. A good dictionary must have certain characteristics mentioned in Crystal (1987as cited in Abdullah, 1995) such as having paper quality, good binding, containing encyclopedic information, clear definitions, giving guidance to usage, being easily accessible, and having idioms, synonyms, antonyms, etc. 
Furthermore, the dictionary is an important pedagogical tool that plays a vital role in various processes of language learning including reading comprehension and vocabulary learning and acquisition. But which kind of a dictionary students should use has become a controversial issue in the literature. Should the dictionary use be determined by students' level or proficiency or other factors? Underhill (1980as cited in Hayati \& Akram, 2006) claims that many high frequency words may be given appropriate treatment and consideration in monolingual dictionaries rather than other dictionaries because these words are widely used in English textbooks. Furthermore, Boxer (1980) as cited in Hayati \& Akram, (2006) also claims that a monolingual dictionary not only demonstrates definitions but also other important aspects. He believes that more encouragement should be given to the use of monolingual dictionary because it promotes fluency by offering definitions in context; in contrast the bilingual dictionaries tend to encourage word for word translation equivalents that may not be appropriate in certain situations and might cause confusion and ambiguity. Moreover, Yorio (1971); and Bensoussan et al. (1984, as cited in Hayati, 2006, p. 126) point out that the bilingual dictionaries seem to give students security of concrete answers, while monolingual dictionaries often force students to guess and predict the meaning, and lead to doubt and confusion. Furthermore, monolingual dictionaries are likely to give a long and confusing description that might not suggest the intended and desired meaning. However, according to Bejoint (1981); quoted in Scholfield, (1982) "those learners who use monolingual dictionaries would help them to get into habit of thinking in the target language" Scholfield, (1982, $p$. 22).

Further, Thompson (1987) and Wingate (2002) as cited in Lew; (2004, p. 4) argue that monolingual dictionaries have more limitations such as the definitions may be too difficult to understand, learners may pass over important information such as semantic restrictions of words, because they are not able to understand the basis of words and the grammatical structure can be complex. In addition, according to Nakamoto (1995), Thompson (1987, p. 282) and Wingate (2002; p. 24 as cited in Lew, 2004, p. 9) bilingual dictionaries have some deficiencies such as reinforcing the learners' tendency to translate from native language and, by encouraging translation; they discourage learners from thinking directly in the foreign language. In addition, they claim these dictionaries do not help learners to develop their academic skills such as paraphrasing, and they give little information about semantically related words such as sense relations (synonyms, antonyms, heteronyms, etc.). However most of the EFL learners prefer the bilingual dictionaries because they are time-saving, straightforward and easy to use.

The most obvious challenge for EFL learners is the language of monolingual dictionaries, as they contain definitions, symbols and other morphological information about the words which are difficult for less proficient students to understand. However, the language in bilingual dictionaries is very straightforward and contains less definitions and morphological information which would encourage EFL learners to choose them.

\subsection{Language Learners and Use of Dictionaries}

Language learners' use of the dictionary has been studied from various perspectives. For example, studies have focused on the accuracy of learners' dictionary use (Nesi and Hail 2002; Gonzales 1999; as cited in Pousi; 2010), the effect of the dictionary use on vocabulary learning and reading comprehension; (Knight ,1994), and on the effect of different types of dictionaries such as bilingual, monolingual and bilingualized dictionaries (Laufer and Hadar 1997; Tomaszczyk 1979). Tomaszczyk (1979) was the pioneer and the first researcher to initiate an investigation into the dictionary use by non-native speakers of English. (Tomaszczyk, 1979, as cited in Ryu, 2005) he conducted astudy based on Polish learners at the university level for foreign language instructors, and translators. Although participants expressed their satisfaction with monolingual dictionaries, the majority preferred to use bilingual dictionaries over monolingual dictionaries. But the current study is focused on EFL foundation students not students who are majoring in English language as in the above mentioned study.

A similar study was conducted by Bejoint (1981) on French EFL students' use of monolingual English dictionaries. The results reveal that only $17 \%$ of the participants preferred the bilingual dictionary in contrast to Tomaszczyk's study. Moreover, recent studies focus on dictionary use training (Atkins and Varantola, 1998; Li, 1998; Hartmann, 1999; and Sanchez, 2005) as cited in Ryu; (2005) in all these studies the majority of the students indicates that they never received dictionary use training. However, a study by Laufer and Hadar (1997) cited in Pousi, (2010, p. 6) on pre-advanced and advanced learners reveals that the unskilled dictionary users performed better in comprehension and production when using a bilingual dictionary, as opposed to using a monolingual one. Moreover, Loucky, (2001) conducted a study on Japanese learner and the use of dictionary and it was found out that the majority of Japanese learners prefer bilingual dictionaries particularly the computerized ones. In addition, a similar study was conducted by Schmitt (1997) as cited in Pousi (2010) to survey Japanese EFL learners' perceptions about the use of bilingual and monolingual dictionaries, and the results indicated that (85\%) of the respondents report that they prefer to use bilingual dictionaries and only (15\%) preferred to use monolingual dictionaries. 
In addition, a study was conducted by Hayati (2005) to investigate the impact of the bilingual dictionary compared with the monolingual on reading comprehension among EFL Iranian intermediate students studying at Shahid Chamran University of Ahwaz. The results indicated that using a dictionary during reading can aid intermediate students to comprehend a text more efficiently. Regarding the effectiveness of the bilingual dictionary, the results reveal that the bilingual dictionary is a powerful and effective pedagogical tool; it can appear as useful as a monolingual one in reading comprehension of intermediate EFL students.In light of the results above, both dictionaries are important, and bilingual dictionaries are the best for beginners and intermediate-level learners and monolingual dictionaries for the advanced-level ones. Therefore, this study is set out to explore the students' and teachers' attitudes and perceptions about the use ofthe dictionary in general, and the monolingual one in particular in both classroom and during exams with special emphasis in EFL context specifically in Caledonian College of Engineering, Sultanate of Oman.

\section{Study Questions}

1. What kind of dictionary do students usually use and why?

2. Which dictionary would they prefer?

3. How can students use the dictionary to enhance learning?

\section{Method}

This study is exploratory in nature in a sense that it attempts to investigate and explore students' and teachers' assumptions and perceptions about dictionary practices in the School of Foundation Studies, Caledonian College of Engineering, Oman; to know which dictionary the students would prefer and to find out possible ways to train students to use dictionary in the best way. The target participants were 20 teachers and 100 students from the School of Foundation Studies, Caledonian College of Engineering. The vast majority of the students are Omani. Their age ranges from (18-22) and they have many things in common such as language, culture, schooling etc. All of them had an average of 10 years of formal instruction in English as a foreign language and were about to complete their foundation courses. Most of them have been educated under the same educational system. They have been using bilingual dictionaries for more than six years up to their third secondary schooling. They are in the intermediate levels and with a relatively good proficiency. The teachers are of different nationalities such as British, Indian, South African, Sudanese, Omani, etc. and they have been teaching English Language in Oman for a couple of years and have substantial experience in teaching English at the tertiary level. They are teaching both elementary and intermediate levels. Questionnaires were used to collect data from 20 teachers and 100 students from the School of Foundation Studies Caledonian College of Engineering, Oman. The questionnaires follow Likert- 3 points scale. A list of statements were constructed on both students' and teachers' perspectives, regarding such issues as students' perceptions about what kind of dictionary they are using, which dictionary they would prefer and the possible ways for helping students to use dictionaries in the best way and teachers and students were asked to choose and select the appropriate statement that they fit their thought. The data was analyzed using frequencies and percentages.

\subsection{Procedures}

Students' questionnaire was administered during classes and students were briefed about the purpose of the study and their queries were taken into consideration. To establish reliability, the questionnaires were piloted before administration to iron the wrinkles out and a new version was drafted that was easier with clear instructions for the students. The content was reworded and irrelevant questions were taken out to secure the intelligibility of the questionnaire.

\section{Results}

These results are subject to limitations and should be treated with caution. The number of participants is only 100 students who are studying in level two (intermediate level) and only 15 teachers which might not be representative sample of the whole population and which might impede generalization of the study.

\subsection{Presentation and Analysis of Data Collected from Students' Questionnaire}

1. What kind of a dictionary are you using mostly?

In response to the question, what kind of a dictionary are you using mostly, 50 students $(50 \%)$ say they prefer to use bilingual dictionariesrather than monolingual and bilingualized ones.

2. How would you rate your use of dictionary?

For the question, how would you rate yourdictionary use, 44 students $(44 \%)$ report that their use of dictionary is good, and 30 students $(30 \%)$ say their use is acceptable, 14 students $(14 \%)$ report that their use is 'very good', and 
12 students (12\%) say their use of dictionary is 'poor' and only 5 students (5\%) say their use is 'extremely poor'.

3. Are you satisfied with the kind of dictionary you use in classroom.

Regarding their satisfaction of the kind of dictionary they use, 35 students (35\%) report that they are somewhat satisfied, and 20 students $(20 \%)$ say they are satisfied and 3 students (3\%) report that they are extremely satisfied, whereas, 32 students (32\%) say they are dissatisfied, and 5 students $(5 \%)$ say they are extremely dissatisfied.Itis quite evident that a considerable number of students think they are unsatisfied with the kind of dictionary they are using which is monolingual dictionary.

4. A Dictionary is an invaluable learning tool for me.

In response to question 4, whether a dictionary is an invaluable learning tool for them or not, 34 students (55\%) agreed, 30 students (30\%) said they weren't sure, and 15 students $(15 \%)$ disagreed, so they believed that it is not a valuable learning tool. This result suggests that majority of the students value the use of dictionary and they believe it is a valuable source.

\section{I like to use a monolingual dictionary.}

As for question 5, whether they like to use monolingual dictionary or not, 24 students (24\%) say they like to use monolingual dictionary and 26 students $(26 \%)$ were 'not sure' and 50 students $(50 \%)$ 'disagreed'. It is very clear that a considerable number of the students donot like to use monolingual dictionary.

\section{I know how to use a dictionary.}

Regarding question 6, whether they know how to use the dictionary effectively or not, and only50 students (50\%), 30 students $(30 \%)$ claim that they are not sure whether they can use the dictionary effectively or not and 20 students $(20 \%)$ disagreed. Therefore, it is quite evident that they do not know how to use the dictionary effectively.

7. I find using a dictionary in the exam helpful to me.

Regarding the use of dictionary in the exam, whether they have found the use of dictionary in the exam helpful, 19 students (19\%) say they are not sure whether it is useful or not, and 63 students $(63 \%)$ claimedthat the use of dictionary is not much useful. This indicates that the bulk majority of the students don not like using a dictionary in the exam.

8. I like using a dictionary during lessons.

As for question 8, whether they like to use dictionaries during lessons, 35 students (35\%) said they like the idea of using dictionaries during lessons, and they like to use it frequently, 21 students $(21 \%)$ report that they are not sure whether they like using it during lessons or not, and 50 students (50\%) 'disagreed'. This suggests that a considerable number of the students are not in favor of using dictionary during lessons.

9. I need more training in using dictionary.

In response to question 9, whether they need training in using dictionary or not, 33 students (33\%) agreed, 21 students (21\%) were 'not sure', and 46 students (46\%) 'disagreed'.

10. I have learnt a lot from my "techno terms dictionary".

Concerning question 10, whether they have learnt from their self-made dictionary or not, 69 students $(69 \%)$ report by 'agree', and 18 students (18\%) respond by 'notsure' and 20 students $(20 \%)$ said they 'disagree with the statement. This analysis revealed that the vast majority of the students agreed that they have learnt a lot from their self-made dictionaries (techno terms dictionaries). This dictionary contains all the technical terms related to their potential specialty in engineering.

\section{I don't like to use a dictionary.}

In response to question 11, whether they dislike the use of dictionary, 42 students (42\%), 'agreed', 20 students (20\%) say they are not sure 42 students $(42 \%)$, 'disagreed'. Therefore, it is quite clear that a substantial number of the students didn't like to use the dictionary in classroom.

In light of the above discussion,students' and teachers' responses and with regard to the study questions, Omani students prefer bilingual dictionaries because they think they are practical and straightforward and time-saving and they do not like to use monolingual dictionaries because they are confusing to them and they find difficulty in using them and they are time-consuming during lessons.

\subsection{Presentation of Teachers' Questionnaire Results}

1. Is it effective to use a monolingual dictionary in the classroom than bilingual one?

With regard to question no 1 , the effectiveness of monolingual dictionaries over the bilingual one, 10 teachers $(50 \%)$ 
believe that monolingual dictionaries are almost always more effective than bilingual ones while, 5 teachers (25\%) felt they were occasionally more effective, 3 teachers said they were effective all the time and only 1 teacher thought they were rarely effectiveat all. Therefore, it appears that the vast majority of the teachers assume that monolingual dictionary is more useful and effective than bilingual one.

2. Using a dictionary in the classroom makes my students more competent and confident.

Concerning teachers' responses to question 2, 15 teachers (75\%) agreed the use of dictionary in classroom would make their students more competent and confident while $20 \%$ of teachers were 'not sure', and only (15\%) 'disagreed'. Thus, it is clear that the vast majority of teachers assume that the use of dictionary in classroom is effective and useful for their students.

3. I like the idea of using a monolingual dictionary.

$(85 \%)$ of teachers 'agreed' that that they liked the idea of using a monolingual dictionary in class and only (15\%) disagreed and no one respond by 'not sure'. This result revealed teachers' preference monolingual dictionaries not bilingual ones.

4. Using a dictionary in the classroom may invalidate the exam results.

As for question no $4,20 \%$ of the teachers assume that using dictionary in classroom may not validate the exam results, $(25 \%)$ of them were not sure', and $45 \%$ 'disagreed'. Therefore, it is clear that the majority of the teachers assume that the use of dictionary invalidates the results.

5. Using a dictionary in classroom is time-consuming and can slow down the teaching learning process.

In response to the question about whether using a dictionary in classroom is time-consuming and can slow down the teaching learning process, $35 \%$ of teachers 'agreed' with the statement, and $15 \%$ were 'not sure', $40 \%$ 'disagreed'.

6. Using a dictionary in classroom has helped my students to learn better.

Regarding question 6, whether using a dictionary in classroom has helped their students to learn better, (55\%) teachers 'agreed' $(20 \%)$ were 'not sure', and only (15\%) 'disagreed'. This result is inconsistent with students' response to item (8) about using dictionaries in classroom. This finding supports the use of dictionary in classroom.

7. My students have learnt how to use monolingual dictionary effectively.

With regard to question 7, whether teachers believe their students have learnt how to use monolingual dictionary effectively, (75\%) of teachers 'agreed', and (15\%) were 'not sure', and only $(10 \%)$ 'disagreed'. This result is inconsistent with students' responses in item (5) which indicates that (50\%) of them reported that they do not know how to use monolingual dictionary effectively.

\section{Students' over-reliance on dictionary helps them to learn better}

In response to question no 8 , whether over-reliance on dictionary helps their students to learn better, (15\%) of teachers 'agreed', (40\%) of teachers were 'not sure' and (40\%) of teachers 'disagreed'.It could be arguedthat students' over-reliance on dictionarymay not help students to learn better and gain some guessing inferences skills.

9. My students need more training to use a dictionaryeffectively

Regarding question no 9 , whether their students need more training to use a dictionaryeffectively $(75 \%)$ of teachers 'agreed', and $(5 \%)$ were 'not sure' and $(20 \%)$ of teachers 'disagreed'. This finding confirms that training to use dictionary is important for students to use monolingual dictionary in a proper way. This result reveals the fact that teachers don not provide training in using monolingual dictionaries and instead they encourage their students to use them rather than monolingual ones.

10. I encourage my students to use both monolingual and bilingual dictionaries in classroom.

Concerning whether they encourage their students to use both monolingual and bilingual dictionaries in classroom, $(90 \%)$ of teachers 'agreed', no one was'not sure' and $(10 \%)$ of teachers 'disagreed'. It is quite evident that the great majority of the teacherswho were surveyed like the use of monolingual dictionary and they usually encourage their students to use. This result is inconsistent with teachers' response in items (3) which revealed that (85\%) of teachers "disagreed" on the use of monolingual dictionaries in classroom, however for item (9) the vast majority are in favour of both types of dictionaries and they do encourage their students to use both of them in classroom.

\section{Conclusions \& Recommendations}

To sum up, the study was conducted to explore both teachers' and students' views about the use of monolingual dictionary in an EFL context, specifically in Caledonian College of engineering, Sultanate of Oman. The study results reveal that teachersin this study arein favor of usingmonolingual dictionaries. However, the students 
generally prefer to use bilingual and bilingualized dictionaries. Thereforethe study puts forward the following recommendations to help teachers, practitioners and students improve their practice:

- Omani students are advised not to appeal to a bilingual dictionary, in the first place, but postpone this strategy tothe time when they feel there is no other choice for them to find the word meanings, and electronic pocket dictionaries should be discouraged as they encourage translation and give inaccurate equivalence.

- In order to encourage students to use monolingual dictionaries, teaching dictionary skills should always be integrated with instructions and the dictionary use training should be given priority in English class. Dictionary exercises suchaslooking for a suitable head entry, comprehending the entry, locating the appropriate part of the definition, putting the word within the context should be included in the syllabus.

- All students should be made aware of the types of dictionary they can use, and which ones are the best according to their needs, and teachers should devote time for dictionary training.

- Students should be encouraged to develop and make their own glossaries as the findings of students' questionnaire in item (10) indicates that they like the idea of their self-made dictionaries and they learnt a lot from them.

\section{References}

Abdullah, S. Y. (1995). Awareness of the information in a good learner's dictionary. Unpublished MA thesis, University of Khartoum, Sudan.

Crystal, D. (1987). The Cambridge Encyclopedia of Language. Oxford: Oxford University Press.

Fan, M. Y. (2000). The dictionary look-Up behavior of Hong Kong students: A large -Scale Survey. Educational Journal, 28(1), summer 2000, 123-138.

Fraser, A. C. (1999). The role of consulting a dictionary in reading and vocabulary learning. pp. 73-89. York University. Retrieved on 20 Dec 2010 from http://www.aclacaal.org/Revue/vol-2-nos1-2-art-fraser.pdf

Hayati, \& Fattahzadeh. (2006). The effect of monolingual and bilingual dictionaries onvocabulary recall and retention of EFL learners. The Reading Matrix, 6(2-6), Sept 2006.

Hayati, A. M. (2005). A comparative study of using bilingual and monolingual dictionaries in reading comprehension of intermediate EFL students. The Reading Matrix Journal, 5(2), September 2005, 61-66.

Knight, S. (1994). Dictionary use while reading: The effects on comprehension and vocabulary acquisition for students of different verbal abilities. The Modern Language Journal, 78(3), 285-299. http://dx.doi.org/10.1111/j.1540-4781.1994.tb02043.x

Lew, R. (2004). Which dictionary for whom? Receptive use of bilingual, monolingual and Semi-bilingual dictionaries by Polish learners of English. Published Ph.D. thesis, Published by motivex Poznan, Poland.

Loucky, J, P. (2003). Using computerized bilingual dictionaries to help maximize English vocabulary learning at Japanese Colleges. CALICO JOURNAL, 21(1), 105-129.

Pousi, B. (2010). Training in dictionary use: A teaching intervention in a $9^{\text {th }}$ grade EFL classroom in Finland. Unpublished B.A thesis, University of Jyvaskyla.

Prichard, C. et al. (2008). Defining and measuring selective dictionary use among L2 readers. JALT Proceedings, 926-935. Tokyo.

Ryu, Jesun. (2005). Dictionary use by Korean EFL college students. Yonesi University.Retrieved on 17 October 2010 from http://hompi.sogang.ac.kr/linguistics/\%BE\%F0\%C1\%A4\%BB\%E77/\%C0\%AF\%C1\%A6\%BC\%B1.pdf

Scholfield, P. (2005). Why shouldn't monolingual dictionaries be easy to use as bilingualones? Retrieved December 23, 2010 from http://www.pearsonlongman.com/Dictionaries/pdfs/Mono-Bilingual.pdf

Tono, Y. (n.d.). Interacting with users: research findings in EFL dictionary user studies. Lexicography in Asia Conference, 97-118. Japan. Retrieved on 15 December 2010 from http://lexicon.tufs.ac.jp/ tono/papers/tono1998c.pdf

$\mathrm{Xu}, \mathrm{X}$. (2010). Study on the effect of dictionary use on second language incidental vocabulary acquisition- An empirical study of college English vocabulary learning strategy. Qindao University of Science and Technology, China Academy Publisher. 